and is set to approve several more in the next year or so.

The personalized approach faces two major problems: complex biology and complex economics. The pathway involved is often not well understood, and most targeted drugs are so expensive that health-care systems and insurance companies don't want to pay for them, even if they reduce waste and should therefore save on overall treatment costs in the long term. The drug gefitinib, for example, costs around $€ 20,000$ (US\$28,000) per patient and targets the EGFR pathway, which is disrupted in fewer than $15 \%$ of patients with lung cancer. What's more, targeted drugs need to be accompanied by diagnostic tests to identify suitable patients, yet many health-care systems have no mechanism to pay for the tests. The result is an absurd situation in which expensive drugs can be prescribed without testing, and therefore to some patients who will gain no benefit.

As arguments about the value of personalized medicine rage around the world, France has found its own solution - at least for cancer, where molecular medicine is most advanced. In 2005, the country said it would pay for the treatment of every citizen shown to be likely to benefit from targeted drugs. Its National Cancer Institute set up 28 platforms for molecular genetics at university hospitals and cancer centres with expertise in both molecular and pathological analysis. Biopsies of cancerous tissue from patients all over France are sent to these platforms for a battery of 20 or so genetic tests. If the tissue displays a genetic signature in any molecular pathway targeted by one of the drugs, the patient gets treated with it. The platforms develop the tests themselves, and are already working on a test to accompany a drug that researchers hope will be approved this year for melanoma. Targeted drugs now account for $57 \%$ of France's cancer-treatment budget. The Czech Republic has a similar system.

The model seems to work. The French platforms have so far tested samples from around 15,000 people with lung cancer for alterations in the EGFR pathway. Just over 1,700 patients tested positive and were given gefitinib until they stopped responding (an average of
38 weeks). That has cost France $€ 35$ million. Had all 15,000 patients been given an eight-week course of gefitinib just to see whether they would respond, it would have cost the nation another $€ 69$ million - with no extra benefit.

Some assessments, however, have concluded that personalized drugs do not offer enough benefit to justify the cost. It will not be easy to persuade the spectrum of state health systems and health-insurance companies that personalized medicine makes economic sense. Understandably, they will want a lot more evidence that it works.

Much reluctance also seems to come from a medical profession unused to needing genetic tests to select
"As arguments about the value of personalized medicine rage around the world, France has found its own solution." patients and from inflexible bureaucratic systems. The European Commission's health directorate could help by encouraging European countries to harmonize their health-technology assessments, or even by issuing its own (non-binding) conclusions on which targeted drugs it considers costeffective. And the commission's research directorate could provide greater support for efforts to translate the results of preclinical research on molecular pathways into the clinic, which it plans to do in its 2012 call for proposals.

Amid the excitement and attention paid to cancer, it is crucial to remember that other conditions - such as psychiatric disorders - carry just as great a societal burden, yet remain too poorly understood to benefit. The research directorate has enabled a great deal of fundamental research on animal models designed to understand such complex conditions, and it must continue to do so, in parallel with its translational efforts. We are at the beginning of personalized medicine in the clinic. But we are also just starting to understand the mechanisms behind most of the diseases that are likely to gain the most.

\section{The human epoch}

\section{Official recognition for the Anthropocene would focus minds on the challenges to come.}

$\mathrm{G}$ eologists are used to dealing with heavy subjects, so who better to decide on one of the more profound debates of the time: does human impact on the planet deserve to be officially recognized? Are we living in a new geological epoch - the Anthropocene?

This is no idle conundrum. Although the term has long been used informally to refer to the current, human-dominated phase of Earth's history, a working group of the International Commission on Stratigraphy, the body that defines the divisions of geological time, is studying the case for making it official (see Nature 473, 133; 2011).

The Anthropocene would be a peculiar addition to the geological timescale. So far, it is more a prediction than a fact of Earth's history, because many of its defining features are only starting to register in the rock record. And the driving force behind the geological transition it labels is not a continental rearrangement, massive volcanism or an extraterrestrial impact - forces that have reshaped the planet in the past. Yet the Anthropocene does deserve proper recognition. It reflects a grim reality on the ground, and it provides a powerful framework for considering global change and how to manage it.

Human activity is set to leave an indelible mark on the geological record. Deforestation, mining and road building have unleashed tides

\section{DNATURE.COM} To comment online, click on Editorials at: go.nature.com/xhunqv of sediment down rivers and onto the ocean floor. Fossil-fuel use and land clearance have already emitted perhaps a quarter as much carbon into the atmosphere as was released during one of the greatest planetary crises of the past, the Palaeocene-Eocene Thermal Maximum 55 million years ago. Now, as then, corals and other organisms are recording a global carbon-isotope shift. The increasing acidification of the oceans as they absorb carbon dioxide will dissolve carbonate from deep sediments, and what is likely to be the sixth great mass extinction in Earth's history will gather speed, adding vivid new markers to the record.

But is it too soon to declare an end to the Holocene, the stable, largely benign epoch that has lasted just 11,700 years - a heartbeat in geological time? What impact will an official change in the geological timescale have on the funding and status of Holocene studies? And is it wise for stratigraphers to endorse a term that comes gift-wrapped as a weapon for those on both sides of the political battle over the fate of the planet?

The scale of the changes already under way and the real value of a unified approach to studying human influences on the planet should surely quash these concerns. The Anthropocene is defined not just by climate change or extinctions, but by a linked set of effects on Earth and its biosphere, from perturbations in the nitrogen cycle to the dispersal of species around the globe. Official recognition of the concept would invite cross-disciplinary science. And it would encourage a mindset that will be important not only to fully understand the transformation now occurring but to take action to control it.

Humans may yet ensure that these early years of the Anthropocene are a geological glitch and not just a prelude to a far more severe disruption. But the first step is to recognize, as the term Anthropocene invites us to do, that we are in the driver's seat. 